\title{
Conversion of Landfilled Ash into Hydraulic Cements under Different Environments
}

\author{
Xuefang Wang ${ }^{1}$, Kaize $\mathrm{Zhu}^{2}$, Salina Ramli ${ }^{2}$, Liwei $\mathrm{Xu}^{3}$, Faris Matalkah ${ }^{2}$, Parviz Soroushian ${ }^{2,4}$ and Anagi M Balachandra ${ }^{*}$ \\ ${ }^{1}$ College of Civil Engineering, Fuzhou University, Fuzhou, Fujian, PR China \\ ${ }^{2}$ Department of Civil and Environmental Engineering, Michigan State University, 3546 Engineering Building, E. Lansing, MI, USA \\ ${ }^{3}$ College of Civil Engineering, Fujian University of Technology, 3 Xueyuan Road, University Town, Fuzhou, Fujian, China \\ ${ }^{4}$ Metna Co., 1926 Turner St., Lansing, MI, USA
}

*Corresponding author: Balachandra AM, Metna Co., 1926 Turner Street, Lansing, MI, USA, Tel: 1+ (517) 485-1402; E-mail: abmetnaco@gmail.com Received: October 05, 2017; Accepted: October 26, 2017; Published: November 06, 2017

Copyright: @ 2017 Wang X, et al. This is an open-access article distributed under the terms of the Creative Commons Attribution License, which permits unrestricted use, distribution, and reproduction in any medium, provided the original author and source are credited.

\begin{abstract}
A landfilled coal fly ash was blended with different constituents for achieving a balanced chemistry that suits production of hydraulic cement and concurrent capture of carbon dioxide. The blend of raw materials was processed via input of mechanical energy into hydraulic cements. The input of mechanical energy via milling was performed in three different environments: air, $\mathrm{N}_{2}$ and $\mathrm{CO}_{2}$. The resultant hydraulic cements were characterized through assessment of their specific surface area, microstructure (scanning electron microscopy), chemical bond environment (FTIR), heat of hydration, and $\mathrm{pH}$, total dissolved solids and electric conductivity of their solutions. Mechanical processing of the blend of raw materials was found to transform them into hydraulic cement. The environment of mechanical processing was also found to be an important factor influencing the properties of the resultant cement.
\end{abstract}

Keywords: Landfilled coal fly ash; Mechanical processing; Hydraulic cement; Alkali activation; Mineral carbonation; Capture of carbondioxide

\section{Introduction}

Landfilled coal ash is predominantly fly ash with some bottom ash content. Coal ash is disposed of in landfills either directly or after a period of wet impoundment [1]. Significant quantities of coal ash have been accumulated in landfills over several decades. In the United States, close to 40 million tons of coal ash are disposed of in landfills annually [2]. The landfilled quantities of coal ash in Europe are of the same order of magnitude as in the United States [3].

Coal fly ash has found applications as pozzolan (partial replacement for cement) in Portland cement concrete. Coal fly ash can also be activated with alkalis for production of geopolymer concrete, that is more sustainable than Portland cement concrete [4], and also offers improved durability [5]. The need for curing of the existing classes of geopolymer concrete at elevated temperatures, however, limits their market acceptance [6,7]. Mechanical activation of coal fly ash in the presence of alkalis can reduce the need for thermal curing of alkali activated coal ash. It has been observed that grinding of landfilled coal fly ash improves the uniaxial compressive strength of alkali-activated fly ash from 2.01 MPa (raw fly ash) to $22 \mathrm{MPa}$ (activated fly ash) [8]. Another investigation demonstrated that, after mechanical activation of coal fly ash, $\mathrm{NaOH}$-activated ash could produce a viable compressive strength of $23 \mathrm{MPa}$ after 28 days of room-temperature curing [9]. Similar results were produced in another investigation where $80 \%$ gain in the compressive strength of alkali-activated fly ash subjected to room-temperature curing was realized once the ash was subjected to mechanical activation [10]. Previously a method was developed for capture of carbon dioxide (directly from combustion emissions) into land filled coal ash, and simultaneous transformation of the carbon dioxide and ash with supplementary minerals into a hydraulic binder for heavy metal stabilization [11]. There is further evidence reported in the literature, suggesting that mechanical activation of fly ash via grinding significantly improves the mechanical properties of alkaliactivated ash [12]. It has been reported that the compressive strength of $\mathrm{Cu}-\mathrm{Ni}$ slag geopolymer with the slag milled in $\mathrm{CO}_{2}$ is higher than that obtained with slag milled in air, which was attributed to higher reactivity of the slag particles induced by chemisorption of carbon dioxide molecules in the form of distorted carbonate ions in the course of mechanical activation $[13,14]$. Other investigations have confirmed that the reactivity of slag can be enhanced by grinding in a carbon dioxide atmosphere, producing higher compressive strengths upon alkali activation $[15,16]$.

The work reported herein focused on the effects of mechanical activation via ball-milling, and the environment of mill (air, $\mathrm{N}_{2}, \mathrm{CO}_{2}$ ) on the activity of coal fly ash as an aluminosilicate precursor in production of geopolymer (via alkali activation). $\mathrm{N}_{2}$ was selected as an inert environment where reactions with the mill environment would not be a major factor. Air and $\mathrm{CO}_{2}$ were considered as reactive environments that could affect the performance of the resultant (mechanically activated) coal fly ash.

\section{Materials}

The raw materials used in this process were landfilled coal ash: calcium oxide: basalt: sodium hydroxide at 82:6:6:6 weight ratios. The landfilled coal ash was obtained from local landfilled in Michigan; this ash had been landfilled for 2 years. Typical scanning electron microscope images of the landfilled coal ash are shown in Figure 1. The surface of landfilled ash is not smooth, which may due to hydration and carbonation reactions during the period of disposal in landfill. The 
Citation: Wang X, Zhu K, Ramli S, Xu L, Matalkah F, et al. (2017) Conversion of Landfilled Ash into Hydraulic Cements under Different Environments. Adv Recycling Waste Manag 2: 144. doi:10.4172/2475-7675.1000144

Page 2 of 6

chemical composition of landfilled coal ash is presented in Table 1. It is worth mentioning that basalt generally comprises $\mathrm{SiO}_{2}, \mathrm{Al}_{2} \mathrm{O}_{3}, \mathrm{CaO}$, $\mathrm{FeO}, \mathrm{MgO}$ and $\mathrm{TiO}_{2}$, which are also found in the landfilled coal ash.

\begin{tabular}{|l|l|l|l|l|l|l|l|l|l|l|l|l|l|}
\hline Sample & $\mathbf{S i O}_{2}$ & $\mathbf{C a O}$ & $\mathbf{F e}_{2} \mathbf{O}_{3}$ & $\mathbf{A l}_{2} \mathbf{O}_{3}$ & $\mathbf{S O}_{3}$ & $\mathbf{M g O}$ & $\mathbf{N a}_{2} \mathbf{O}$ & $\mathbf{K}_{2} \mathbf{O}$ & $\mathbf{B a O}$ & $\mathbf{T i O}_{2}$ & $\mathbf{S r O}$ & $\mathbf{P}_{2} \mathbf{O}_{5}$ & others \\
\hline Landfilled ash & 25.21 & 24.08 & 18.46 & 13.12 & 2.27 & 2.9 & 2.8 & 2.4 & 2.44 & 2.37 & 1.47 & 0.95 & 1.08 \\
\hline
\end{tabular}

Table 1: Chemical composition of the landfilled coal ash (wt.\%).
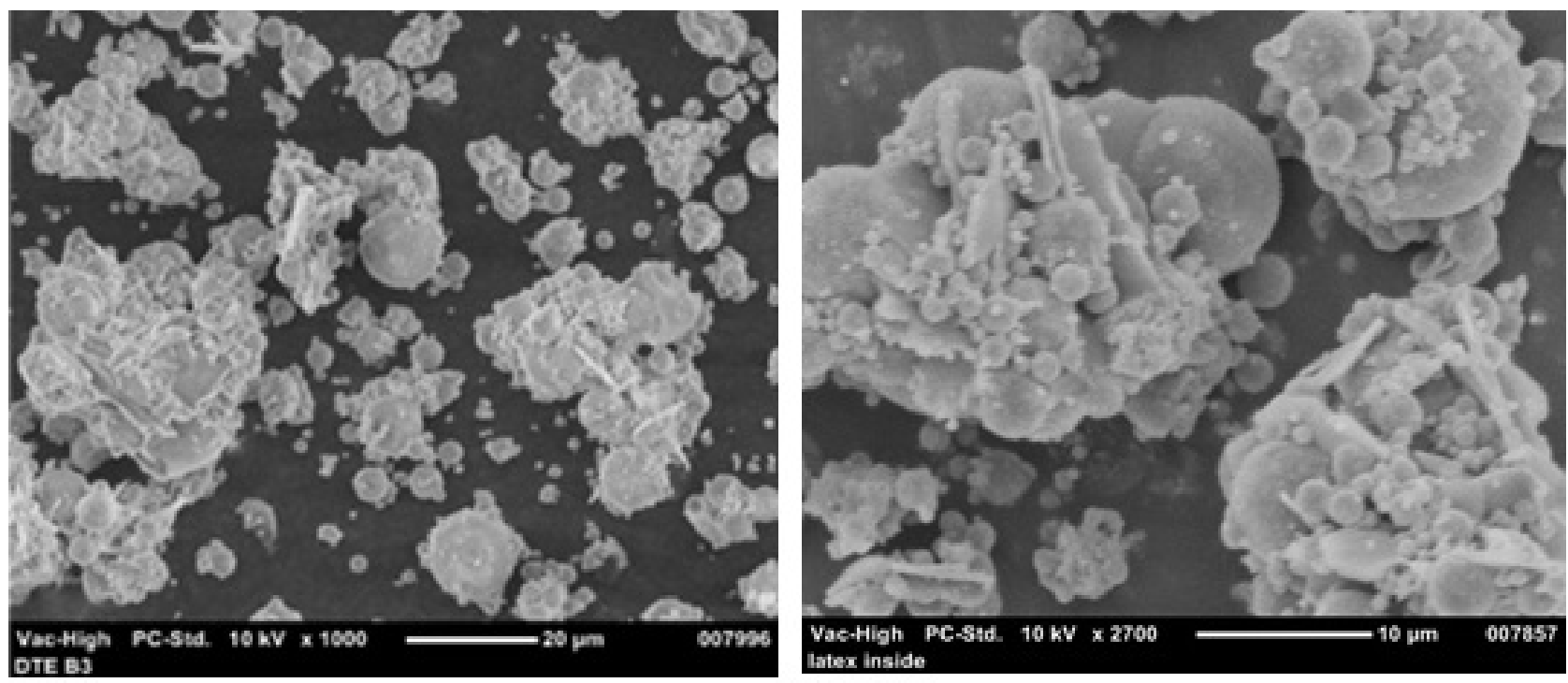

Figure 1: Scanning electron microscope images of the landfilled coal ash.

\section{Methods}

A ball mill with diameter of $140 \mathrm{~mm}$ and height of $140 \mathrm{~mm}$, made of steel, was used at a rotational speed of $40 \mathrm{rpm}$ to mill the geopolymer cement. At each time, $400 \mathrm{~g}$ of raw materials was milled with $4000 \mathrm{~g}$ of steel ball. The milling duration was 4 hours in each of the milling environments (air, $\mathrm{N}_{2}$ and $\mathrm{CO}_{2}$ ). Temperature at the mill surface were monitored using a temperature sensor with data storage capability.

The resulting geopolymer cements were evaluated via FTIR spectroscopy. For this purpose, $2 \mathrm{mg}$ of cement was mixed with $200 \mathrm{mg}$ of $\mathrm{KBr}$, and the dry blend was formed into pellets using a high-pressure injection molding machine. A Jasco FT/IR-4100 spectrometer was used to perform these tests over a measurement range of $400-4000 \mathrm{~cm}^{-1}$.

The $\mathrm{pH}$ values of cements in solution were measured by dissolving 1 $\mathrm{g}$ of the geopolymer cement in $100 \mathrm{~g}$ of distilled water. The solution was placed on a shaker, and the initial $\mathrm{pH}$ values as well as those after 1 hour and 24 hours were measured. The total dissolved content (TDS) and electric conductivity of solutions were also measured in order to gain insight into the dissolution process of the hydraulic binder.

The heat of hydration of cements was measured using the calorimetry test method (ASTM C1679) using an I-cal 2000 HPC calorimeter manufactured by Calmetrix Inc. (Boston, USA). In this test, cement was mixed with water (by hand) at water/cement weight ratio of 0.40 for 30 seconds. The fresh paste was placed inside the calorimeter, and the exothermic heat release was monitored over 24 hours.

A 20 Quart planetary mixer (Hobart A-200) was used to mix the mortar mixtures comprising cement, silica sand, water and super plasticizer. Mixing was performed over 3 minutes at medium speed. The resulting fresh mix was cast into $50 \mathrm{~mm}$ cube molds, and consolidated via external vibration. The water/cement and sand/ cement ratios of mortar mixtures were 0.5 and 2.75, respectively; superplasticizer was used at $0.5 \%$ by weight of cement to raise the fresh mix workability. The specimens were demolded after 24 hours, sealed, and stored at $22 \pm 2{ }^{\circ} \mathrm{C}$ and $50 \pm 5 \%$ humidity. The compressive strength of the cubic test specimens was measured at 7 and 28 days of age per ASTM C109.

\section{Results and Discussion}

\section{Temperature of the mill exterior surface}

Figure 2 shows the powder temperature when geopolymer cement processing via milling was performed in $\mathrm{CO}_{2}$, in air and in $\mathrm{N}_{2}$ environments. The presence of $\mathrm{CO}_{2}$ is observed to induce an early temperature due to the frictional effects during impact of balls and particles [17], and also probably the formation of carbonates as a result of exothermic mechanochemical reactions of the carbon dioxide gas with alkaline earth metal, alkali metal and other constituents of the solid raw materials. Microstructural changes under impact could also 
have thermal implications [18]. The peaks of powder temperature mill after about 3 hours in the presence of $\mathrm{CO}_{2}$, and then starts to drop gradually. However the peak powder temperature is showed after 30 min in air milling. The trends in the exterior surface temperature development of the mill with the milling duration are quite different in the presence of nitrogen. There is actually a drop in temperature during the first 20 minutes of milling, after which the temperature starts to rise slowly and seems to reach a plateau at $110 \mathrm{~min}$, and then strats to drop gradurally. Compare to initial temperature, the peak temperature of powder during milling in $\mathrm{CO}_{2}$, in air and in $\mathrm{N}_{2}$ increase $5.8^{\circ} \mathrm{C}, 2.3^{\circ} \mathrm{C}$ and $1.8^{\circ} \mathrm{C}$. While the eventual temperature rise can be explained by the frictional impact of balls and solid raw materials, microstructural changes and mechanochemical reactions, the initial drop in temperature could result from the evaporation of the water present in solid raw materials in the $\mathrm{N}_{2}$ environment, combined with the reduced extent of (exothermic) mechanochemical reactions due to the inert nature of $\mathrm{N}_{2}$.

The sharp contract between the powder temperature development during milling in $\mathrm{CO}_{2}$ versus air points at the role played by $\mathrm{CO}_{2}$ to enhance mechanochemical effects. A host of other phenomena also occur during milling that could be affected by the milling environment. Examples include comminution (particle size reduction) accompanied with formation of new surfaces, crystal deformation, defect formation, shear stresses buildup, reduction of crystallite size, aggregation of crystallites, local (and momentary) rise of temperature and pressure, phase transitions, amorphization, chemical bonds breakage, acceleration of diffusion processes [18].

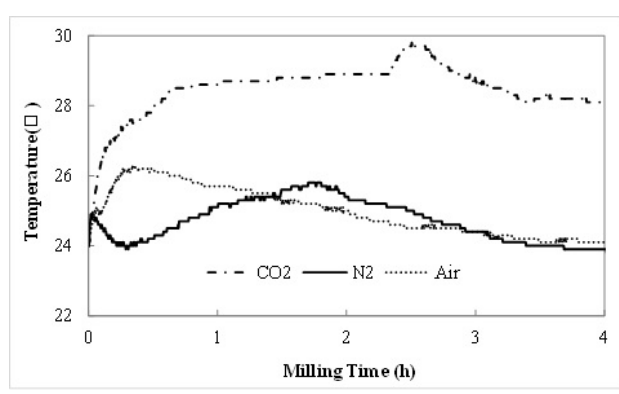

Figure 2: Development of the powder temperature with duration of milling in $\mathrm{CO}_{2}$, in air and in $\mathrm{N}_{2}$.

\section{Specific surface area and morphology}

As shown in Figure 3, the specific surface area of the geopolymer cement milled in air is the lowest, and that milled in $\mathrm{CO}_{2}$ atmosphere is largest (1.19 times of that milled in air). The specific surface area of the geopolymer cement milled in $\mathrm{N}_{2}$ is close to but still lower than that milled in $\mathrm{CO}_{2}$. These results are similar to those reported by Rakhimov [19] and Kalinkina $[15,20]$ where the specific surface area of slag geopolymer milled in $\mathrm{CO}_{2}$ was found to be higher than that milled in air. After milling in air, a small amount of powder bonded to internal surface of the mill; this phenomenon was less pronounced when milling was performed in $\mathrm{N}_{2}$, and it did not happen when milling was performed in $\mathrm{CO}_{2}$. It should be noted that $\mathrm{N}_{2}$ and $\mathrm{CO}_{2}$ were input continuously from outside the mill; this was not the case when milling was performed in air. One may hypothesize that the gas flow (that was absent for milling in air) would enhance the dispersion of powder and thus the efficiency of the impact energy input to the powder. This effect could be more pronounced in $\mathrm{CO}_{2}$ with a density that is 1.5 times higher than that of $\mathrm{N}_{2}$. These factors could influence the rise in specific surface area when milling was performed in $\mathrm{N}_{2}$ and especially in $\mathrm{CO}_{2}$.

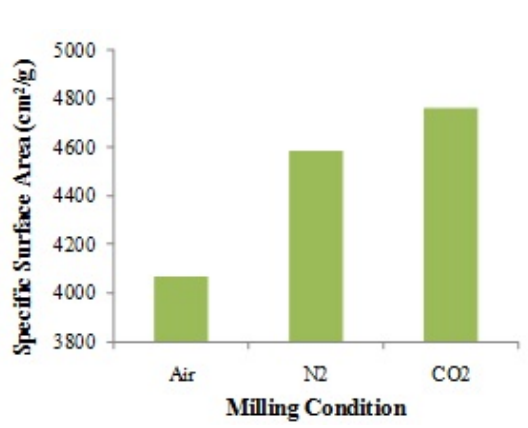

Figure 3: Specific surface area of geopolymer cement.

Scanning electron micrographs of geopolymer cements produced via milling in $\mathrm{N}_{2}$, air and $\mathrm{CO}_{2}$ are shown in Figure 4. These images suggest that the extent of mechanochemical reactions was probably the least when milling was performed in $\mathrm{N}_{2}$, which could be explained by the inert nature of nitrogen that does not promote solid-gas reaction under input of impact energy. The reactive nature of air and $\mathrm{CO}_{2}$ seem to produce morphological changes that could point at intense mechanochemical reactions. Reactions involving carbon dioxide and the silicate constituents of raw materials could be summarized as [21]:

$$
(\mathrm{Ca}, \mathrm{Mg}) \mathrm{SiO}_{3}(\mathrm{~s})+\mathrm{CO}_{2}(\mathrm{~g}) \rightarrow(\mathrm{Ca}, \mathrm{Mg}) \mathrm{CO}_{3}(\mathrm{~s})+\mathrm{SiO}_{2}(\mathrm{~s})
$$

This carbonation reaction could also destabilize the structure of silicates and promote other mechanochemical reactions.

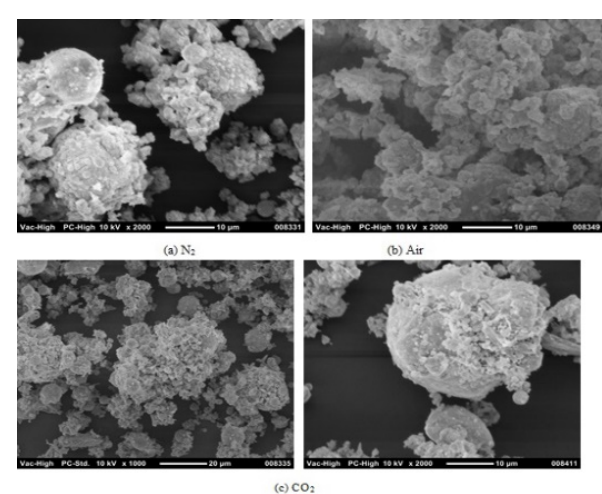

Figure 4: Scanning electron micrographs of geopolymer cement milled in different environments.

\section{FTIR spectra}

The FTIR spectra of geopolymer cement before and after milling in air, $\mathrm{N}_{2}$ and $\mathrm{CO}_{2}$ are presented in Figure 5. Before milling, the peaks at $1460 \mathrm{~cm}^{-1}$ and $880 \mathrm{~cm}^{-1}$ were attributed to the presence of carbonate on the surface [22-24] that form upon exposure of the raw materials to air. The peaks at about $3450 \mathrm{~cm}^{-1}$ and $1650 \mathrm{~cm}^{-1}$ can be attributed to the absorbed atmospheric water. The $\mathrm{Si}-\mathrm{O}-\mathrm{Si}$ stretching vibration produces the peak 985 and $1080 \mathrm{~cm}^{-1}$, and the $\mathrm{Si}-(\mathrm{OH})$ stretching vibration produces the peak between 1094 and $1140 \mathrm{~cm}^{-1}$ [25-28]. 
Peaks below $750 \mathrm{~cm}^{-1}$ can be attributed to $\mathrm{M}-\mathrm{O}$ vibrations, where $\mathrm{M}$ is $\mathrm{Al}$ or $\mathrm{Ca}[23,29]$. The band around $3640 \mathrm{~cm}^{-1}$ detected in all samples reflects the presence of sodium hydroxide. After mechanical activation, the band at $689 \mathrm{~cm}^{-1}$ is shifted to around $710 \mathrm{~cm}^{-1}$, which points at the formation of new compounds via chemical reaction. The peak at 3640 $\mathrm{cm}^{-1}$ after milling is smaller than that before milling, which suggests that part of sodium hydroxide has been consumed in mechanochemical reactions.

After milling in $\mathrm{CO}_{2}$, the spectral peaks related to $\mathrm{CO}_{3}{ }^{2-}$ of 2520 $\mathrm{cm}^{-1}, 1400 \mathrm{~cm}^{-1}$ and $870 \mathrm{~cm}^{-1}$ are sharper and more clear when compared with those observed after milling in air or in $\mathrm{N}_{2}$, which can be attribute to the mechanochemical carbonation reactions during milling. After $\mathrm{CO}_{2}$ milling, bands appeared around $1663 \mathrm{~cm}^{-1}$ and $1622 \mathrm{~cm}^{-1}$, and the band around $1640 \mathrm{~cm}^{-1}$ disappeared; a new band at $1921 \mathrm{~cm}^{-1}$ and the Si-O-Al vibration peak at $815 \mathrm{~cm}^{-1}$ [25] also appeared for the geopolymer cement processed via $\mathrm{CO}_{2}$ milling. In the case of milling in $\mathrm{N}_{2}$, the peaks associated with water at $1640 \mathrm{~cm}^{-1}$ and $3400 \mathrm{~cm}^{-1}$ are relatively weak (compared to all other spectra), pointing at the greater loss of moisture during milling in $\mathrm{N}_{2}$. This phenomenon was relies upon earlier to explain the cooling effects observed when milling was performed in $\mathrm{N}_{2}$.

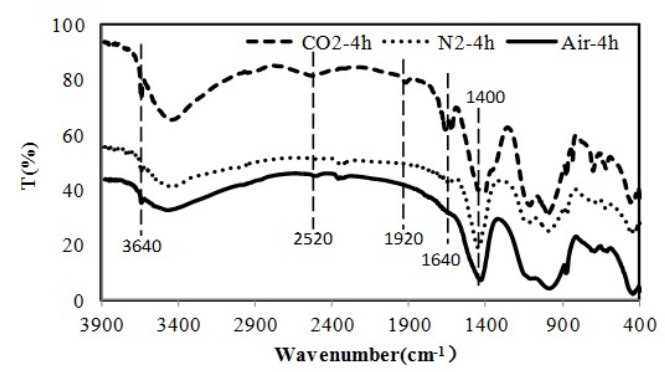

Figure 5: FTIR spectra of blended raw materials (without milling), and geopolymer cements processed via milling for 4 hours in air, $\mathrm{CO}_{2}$ and $\mathrm{N}_{2}$.

\section{$\mathrm{pH}$, total dissolved solids and electrical conductivity in solution, and loss on ignition}

The $\mathrm{pH}$ value of geopolymer cement (in solution) prior to and after milling in air, $\mathrm{N}_{2}$ and $\mathrm{CO}_{2}$ are show in Figure 6. After milling in air and in $\mathrm{N}_{2}$, the $\mathrm{pH}$ value of geopolymer cement increased from 12.31 to 12.49. This can be interpreted as a rise in the activity of the blend of raw materials after mechanochemical transformation into geopolymer cement. Mechanochemical processing in $\mathrm{CO}_{2}$, on the other hand, reduced the $\mathrm{pH}$ value due to the formation of acidic carbonates. The highest $\mathrm{pH}$ value was obtained in $\mathrm{N}_{2}$, which could be due to some carbonation reactions when milling was performed in air. The total dissolved solids (TDS) increased (Figure 7) upon milling of raw materials in $\mathrm{N}_{2}$ and in air, reflecting the greater activity of the mechanochemically processed geopolymer cement. The drop in TDS after milling in $\mathrm{CO}_{2}$ can be attributed to the reduced solubility of the mechanochemically produced carbonates. The trends in electrical conductivity (Figure 8 ) are similar to those observed with $\mathrm{pH}$ and TDS test results, and can be explained similarly.

The LOI values (Figure 9) were highest after milling in $\mathrm{CO}_{2}$, and lowest after milling in $\mathrm{N}_{2}$. This observation could be attributed to the mecahnochemical formation of carbonated when milling was performed in air and especially in $\mathrm{CO}_{2}$.

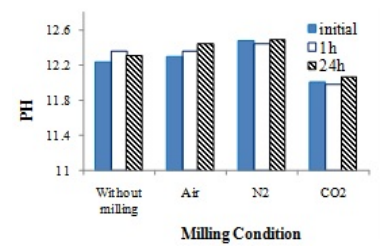

Figure 6: The $\mathrm{pH}$ values of geopolymer cement in solution: initial, 1 $\mathrm{hr}$ and $24 \mathrm{hr}$ values.

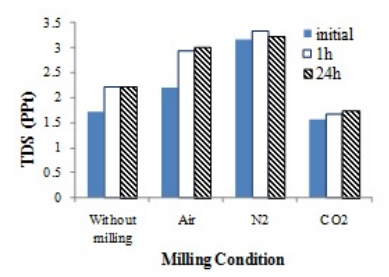

Figure 7: The TDS values of geopolymer cement in solution: initial, $1 \mathrm{hr}$ and $24 \mathrm{hr}$ values.

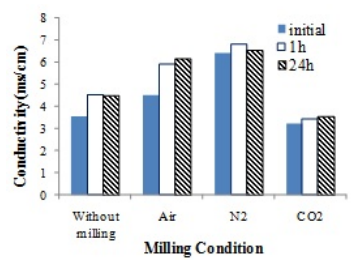

Figure 8: The electrical onductivity values of geopolymer cementin solution: initial, $1 \mathrm{hr}$ and $24 \mathrm{hr}$ values.

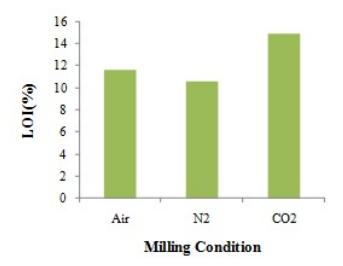

Figure 9: LOI values of geopolymer cement.

\section{Heat of hydration}

The rate and the cumulative heat release during hydration of geopolymer cements processed mecahnochemically in air, $\mathrm{N}_{2}$ and $\mathrm{CO}_{2}$ are presented in Figure 10. After milling in $\mathrm{N}_{2}$ and in air, the initial rates of heat release are higher, resulting in higher cumulative heat release. Milling in $\mathrm{N}_{2}$ produced the highest total heat release. Both the rate and the cumulative heat release are the lowest for the geopolymer cement processed via milling in $\mathrm{CO}_{2}$. Geopolymer cements processed via milling in air and in $\mathrm{N}_{2}$ exhibit only one exothermic peak after 
Page 5 of 6

about 2 minutes, while two peaks are observed after about 3.2 and 16.5 minutes for milling in $\mathrm{CO}_{2}$. The mechanochemical effects of milling seem to have accelerated the rate of exothermic reactions [30,31]. This is indicative of the mechanical activation effects of milling. It has been reported [31] that the initial peak in hydration of geopolymer is related to the destruction of $\mathrm{Ca}-\mathrm{O}, \mathrm{Mg}-\mathrm{O}, \mathrm{Si}-\mathrm{O}-\mathrm{Si}, \mathrm{Al}-\mathrm{O}-\mathrm{Al}$ and $\mathrm{Al}-\mathrm{O}-\mathrm{Si}$ bonds, and the second peak is due to the formation of Si-Al bonds. Higher $\mathrm{pH}$ values may be correlated with the higher rate of bond destruction that generates higher heats of hydration [32-34].

Due to carbonation, the $\mathrm{pH}$ value of geopolymer cement milled in $\mathrm{CO}_{2}$ is the lowest. This lowers the dissolution of iron and the formation of $\mathrm{Si}-\mathrm{Al}$ bonds, thus lowering the heat of hydration. It is possible that delayed formation of $\mathrm{Si}-\mathrm{Al}$ bonds produces the second exothermic peak for the cement processed in $\mathrm{CO}_{2}$. The $\mathrm{pH}$ value of the cement processed in $\mathrm{N}_{2}$ is the highest, which can be used to explain its high rate and extent of heat release.

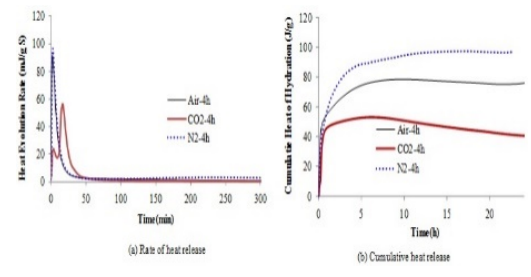

Figure 10: Heat of hydration test results for geopolymer cements processed via milling in different environments.

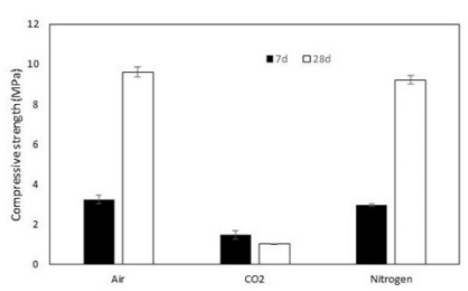

Figure 11: Compressive strength test results at 7 and 28 days of age for mortar specimens prepared with cements processed via milling in air, $\mathrm{CO}_{2}$ and $\mathrm{N}_{2}$ atmospheres.

\section{Compressive strength}

The compressive strength test results at 7 and 28 days of age are presented in Figure 11 for mortar mixtures prepared with different cements. Cements prepared via milling in air and in nitrogen produce comparable compressive strength values. The cement processed via milling in carbon dioxide, however, produced relatively low values of compressive strength. This could be attributed to the lower $\mathrm{pH}$ values obtained with the cement milled in carbon dioxide. This finding implies that carbon dioxide was captured by the cement milled in $\mathrm{CO}_{2}$, and suggests that restoring the $\mathrm{pH}$ value of this cement by introduction of alkaline materials either prior to or after milling could feasibly raise the compressive strength obtained with this cement.

\section{Conclusion}

1. Landfilled ash when blended with basalt, $\mathrm{CaO}$ and $\mathrm{NaOH}$ produces a desired chemistry for production of a hydraulic cement. The blend of raw materials can be transformed into a hydraulic cement via input of mechanical energy.

2. The environment in which the blend of raw materials is transformed into a hydraulic cement via input of mechanical energy influences the nature of reactions and the end product properties. When input of mechanical energy (via ball-milling) was done in a $\mathrm{CO}_{2}$ environment, the temperature measured on the mill surface increased initially, and then decreased. When milling was performed in $\mathrm{N}_{2}$, on the other hand, temperature at the mill surface decreased with time. This could be partly due to exothermic reactions involving carbon dioxide during milling, that would not occur in an inert $\mathrm{N}_{2}$ environment.

3. Milling in $\mathrm{CO}_{2}$ environment transformed the calcium or magnesium silicates present in coal fly ash into carbonates. This seemed to cause release of smaller fly ash particles that are encapsulated in larger ash particles.

4. Input of mechanical energy activated the blend of raw materials. In an aqueous solution of the mechanochemically produced cement showed higher values of $\mathrm{pH}$, total dissolved solids (TDS) and electric conductivity compared to that of blended raw materials. These values were lowest when milling was performed in $\mathrm{CO}_{2}$ that can be explained by the carbonation reactions that take place when processing is performed in a $\mathrm{CO}_{2}$ environment. Milling in air versus $\mathrm{N}_{2}$ produced somewhat lower values of $\mathrm{pH}$, TDS and conductivity in solution that could be explained by some carbonation that takes place in air.

5. The milling atmosphere affects the hydration heat of geopolymer cement. Due to mechano-chemical activation, the appearance of exothermic peak is appears earlier than that of previous test of without milling geopolymer. Milling in air and in nitrogen produced particularly high rates of heat release, and only one exothermic peak. Milling in $\mathrm{CO}_{2}$, on the other hand, produced two peaks and lower rates of heat release. The cumulative heat release associated with hydration of the resultant cement was also smaller when milling was performed in $\mathrm{CO}_{2}$. The relatively low rate and extent of heat release by the cement processed in $\mathrm{CO}_{2}$ can be explained based on its low $\mathrm{pH}$ value in solution that delays formation of $\mathrm{Si}-\mathrm{Al}$ bonds. Delayed formation of these bonds could explain the second exothermic heat release peak observed with the cement processed in $\mathrm{CO}_{2}$. Processing in nitrogen, on the other hand, produces cements with relatively high $\mathrm{pH}$ values in solution. This accelerates the rate of hydration reactions and thus heat release.

6. The mortar compressive strengths produced with cements processed via milling in air and nitrogen were comparable. The cement milled in $\mathrm{CO}_{2}$, however, produced relatively low compressive strengths. This was attributed to the reduced $\mathrm{pH}$ value of the cement milled in $\mathrm{CO}_{2}$. The compressive strength obtained with this cement could be feasibly raised by increasing the alkali content of raw materials.

\section{Acknowledgement}

The authors are thankful to the U.S. Department of Energy for financial support of this investigation under Award No. DESC0015197. 
Citation: Wang X, Zhu K, Ramli S, Xu L, Matalkah F, et al. (2017) Conversion of Landfilled Ash into Hydraulic Cements under Different Environments. Adv Recycling Waste Manag 2: 144. doi:10.4172/2475-7675.1000144

Page 6 of 6

\section{References}

1. Mishra DP, Das SK (2013) Application of polymeric flocculant for enhancing settling of the pond ash particles and water drainage from hydraulically stowed pond ash. Intern J Mini Sci Technol 23: 21-26.

2. Zand B (2009) An experimental investigation on liquefaction potential and post-liquefaction shear strength of impounded fly ash. Fuel 88: 1160-1166.

3. Sushil S, Batra V (2006) Analysis of fly ash heavy metal content and disposal in three thermal power plants in India. Fuel 85: 2676-2679.

4. Duxson P (2007) The role of inorganic polymer technology in the development of green concrete. Cement Conc Res 37: 1590-1597.

5. Deventer V, Provis JL, Duxson P (2012) Technical and commercial progress in the adoption of geopolymer cement. Minerals Eng 29: 89-104.

6. Palomo A, Grutzeck M, Blanco M (1999) Alkali-activated fly ashes: a cement for the future. Cement Conc Res 29: 1323-1329.

7. Barbosa VF, MacKenzie KJ (2003) Thermal behaviour of inorganic geopolymers and composites derived from sodium polysialate. Materials Res Bullet 38: 319-331.

8. Mucsi G (2015) Control of geopolymer properties by grinding of land filled fly ash. Intern J Min Process 143: 50-58.

9. Somna $\mathrm{K}$ (2011) $\mathrm{NaOH}$-activated ground fly ash geopolymer cured at ambient temperature. Fuel 90: 2118-2124.

10. Temuujin J, Williams RP, Riessen AV (2009) Effect of mechanica activation of fly ash on the properties of geopolymer cured at ambient temperature. J Mat Process Technol 209: 5276-5280.

11. Balachandra AM (2017) Development of Refined Chemistries and Processing Methods for Integration of Carbon Dioxide into a Hydraulic Binder for Effective Heavy Metal Immobilization. JOJ Material Sci 2: 555-593.

12. Aydin S, Karatay C, Baradan B (2010) The effect of grinding process on mechanical properties and alkali-silica reaction resistance of fly ash incorporated cement mortars. Powder Technol 197: 68-72.

13. Kalinkin AM (2012) Geopolymerization behavior of $\mathrm{Cu}-\mathrm{Ni}$ slag mechanically activated in air and in $\mathrm{CO}_{2}$ atmosphere. Intern $\mathrm{J}$ Min Process 113: 101-106.

14. Alex TC (2013) Utilization of zinc slag through geopolymerization: Influence of milling atmosphere. Interna J Mineral Process 123: 102-107.

15. Kalinkina EV (2014) Binding properties of ferromagnesian slags after mechanical activation with alkaline-earth carbonates. Inorganic Mat 50: 1179-1184.

16. Kalinkina E (2015) Interaction of magnesia-ferriferous slag with sodium hydroxide solutions: Experimental and physicochemical modeling. Russian J App Chem 88: 1127-1133.

17. Takacs L, McHenry JS (2006) Temperature of the milling balls in shaker and planetary mills. J Mat Sci 41: 5246-5249.

18. Ahmadian Baghbaderani H, Rahimipour MR, Delshad Chermahini M (2016) A combined experimental and modeling study of thermodynamics and kinetics of mechanochemical treatment for synthesis of $\mathrm{Ni} 0.5 \mathrm{Co} 0.5 \mathrm{Fe}_{2} \mathrm{O}_{4}$. Mat Des 95: 54-62.

19. Rakhimova NR, Rakhimov RZ (2014) A review on alkali-activated slag cements incorporated with supplementary materials. J Sustain Cem Based Mat 3: 61-74.

20. Kalinkin A (2013) Geopolymers Based on Mechanically Activated NonFerrous Slags. Chem Sustain Develop 6: 647-655.

21. Montes-Hernandez G (2009) Mineral sequestration of CO(2) by aqueous carbonation of coal combustion fly-ash. J Hazard Mater 161: 1347-1354.

22. Kalinkin A (2005) Chemical interaction of calcium oxide and calcium hydroxide with $\mathrm{CO} 2$ during mechanical activation. Inorg Mat 41: 1073-1079.

23. $\mathrm{Qu} \mathrm{J}$ (2016) Effect of anion addition on the syntheses of $\mathrm{Ca}-\mathrm{Al}$ layered double hydroxide via a two-step mechanochemical process. App Clay Sci 125: 267-270.

24. Dhamal S (2013) Chemical Investigations of Some Commercial Samples of Calcium Based Ayurvedic Drug of Marine Origin: Kapardika Bhasma. J Pharm Biol Sci 6: 5-12.

25. Barbosa VF, MacKenzie KJ, Thaumaturgo C (2000) Synthesis and characterisation of materials based on inorganic polymers of alumina and silica: sodium polysialate polymers. Intern J Inorg Mat 2: 309-317.

26. Bange JP, Patil LS, Gautam DK (2008) Growth and Characterization of $\mathrm{Sio}_{2}$ films deposited by Flame Hydrolysis Deposition System for Photonic Device Application. Progress Electromag Res 3: 165-175.

27. Swedlund PJ, Miskelly GM, McQuillan AJ (2009) An attenuated total reflectance IR study of silicic acid adsorbed onto a ferric oxyhydroxide surface. Geochimica et Cosmochimica Acta 73: 4199-4214.

28. Gaggiano R (2013) An infrared spectroscopic study of sodium silicate adsorption on porous anodic alumina. Surf Interf Anal 45: 1098-1104.

29. Puertas F, Fernández-Jiménez A (2003) Mineralogical and microstructural characterisation of alkali-activated fly ash/slag pastes. Cement Concrete Compo 25: 287-292.

30. Ogino SI, Sato Y (2006) Relation of the number of cross-links and mechanical properties of multi-walled carbon nanotube films formed by a dehydration condensation reaction. J Phy Chem 110: 23159-23163.

31. Pacheco-Torgal FJ, Gomes C, Jalali S (2008) Alkali-activated binders: A review: Part 1. Historical background, terminology, reaction mechanisms and hydration products. Cons Build Mat 22: 1305-1314.

32. Fernández-Jiménez A (2006) The role played by the reactive alumina content in the alkaline activation of fly ashes. Micropor Mesopo Mat 91: 111-119.

33. Petermann JC, Saeed A, Hammons MI (2010) Alkali-activated geopolymers: A literature Review. App Res Assoc Inc. Panama City, FL.

34. Xie Z, Xi Y (2001) Hardening mechanisms of an alkaline-activated class $F$ fly ash. Cem Conc Res 31: 1245-1249. 